\title{
APRENDIZAGEM ORGANIZACIONAL
}

A literatura sobre Aprendizagem Organizacional tem avançado muito nos últimos anos não somente no volume de publicações, mas também descortinando outras dimensões desse campo de estudo. A pesquisa no tema apresenta um legado de mais de 30 anos, com crescimento exponencial a partir da década de 1990. Desde então, desenvolveram-se diferentes investigações acerca de aprendizagem nas organizações, o que contribuiu para a consolidação e o progresso nesse campo de estudo multifacetado e multidisciplinar. As diferentes perspectivas utilizadas para olhar esse fenômeno identificam e expressam várias preocupações, delineando uma agenda para estudos futuros. Claudia Simone Antonello, professora do PPGA-UFRGS, recomenda as seguintes obras:

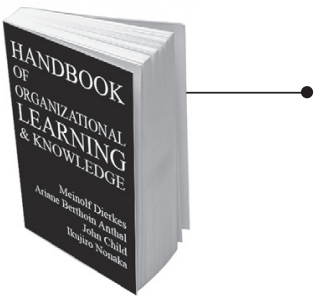

HANDBOOK OF ORGANIZATIONAL LEARNING AND KNOWLEDGE. Meinolf Dierkes, Ariane Berthoin Anthal, John Child e Ikujiro Nonaka (Eds.). Oxford: Oxford University Press, 2001. 979 p.

Trata-se de uma coletânea de textos de reconhecidos pesquisadores que oferece ao leitor uma ampla visão da aprendizagem organizacional e de temas relacionados ao conhecimento nas organizações. Resume e analisa o estado da arte, e apresenta diferentes abordagens teóricas, aplicações e práticas, que enriquecem o debate sobre as debilidades e forças dos estudos em Aprendizagem Organizacional.

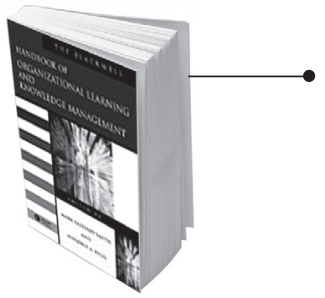

THE BLACKWELL HANDBOOK OF ORGANIZATIONAL LEARNING AND KNOWLEDGE MANAGEMENT. Mark EasterbySmith e Marjorie A. Lyles (Eds.). Oxford: Blackwell Publishing Ltd., 2003. 676 p.

Diferentemente de Cohen e Sproull (1995) na obra Organizational Learning, os editores decidiram, em vez de republicar clássicos, sistematizar textos predominantemente conceituais que abordam o atual debate, demonstrar o desenvolvimento de trabalhos anteriores e apresentar temas futuros que cobrem tópicos relacionados à Aprendizagem Organizacional e à Gestão do Conhecimento. Embora ainda não consigam estabelecer uma aproximação mais definitiva dos dois temas, trata-se de importante contribuição ao estabelecimento de um diálogo entre esses campos, refletindo criticamente sobre as origens dos conceitos, teorias e estudos.

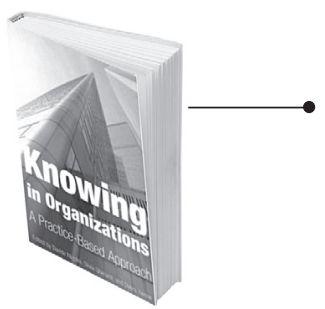

KNOWING IN ORGANIZATIONS: A Practice-Based Approach. Davide Nicolini, Silvia Gherardi e Dvora Yanow (Eds.). New York: M.E. Sharpe, 2003. 280 p.

A obra reúne estudos que exploram as implicações para a pesquisa da noção de que aprendizagem organizacional e conhecimento são fenômenos principalmente sociais e culturais. Apresentam o que denominam uma abordagem baseada em prática para a compreensão desses fenômenos, a partir de diferentes e influentes perspectivas.

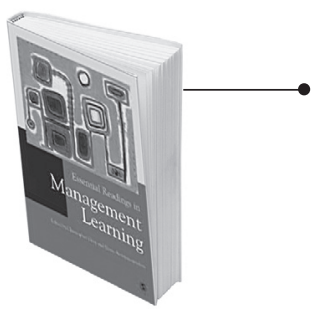

ESSENTIAL READINGS IN MANAGEMENT LEARNING. Christopher Grey e Elena Antonacopoulou (Eds.). Thousand Oaks, CA: Sage Publications, 2004. 440 p.

Obra rica em perspectivas para apresentar três tópicos considerados fundamentais no processo de desenvolvimento do conhecimento, proporcionando ao leitor uma apreciação do campo de Aprendizagem Organizacional durante a última década. Enfatiza a importância do conhecimento gerado pela prática social. Discorre sobre tópicos específicos: cultura, transferência, mecanismos e narrativas de aprendizagem, e a necessidade de reflexão sobre as práticas administrativas.

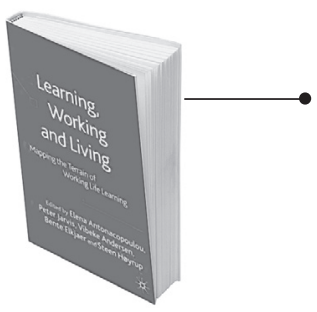

LEARNING, WORKING AND LIVING: Mapping the Terrain of Working Life Learning. Elena Antonacopoulou, Peter Jarvis, Vibeke Andersen, Bente Elkjaer, Steen Høyrup. New York: Palgrave Macmillan, 2005. 272 p.

Para os autores, a natureza social da aprendizagem tem-se orientado segundo a visão de ela atuar como uma maneira de promover o controle, negligenciando perspectivas que considerem algumas dimensões desse fenômeno no contexto organizacional. Assim, eles apresentam e analisam novos modos de compreender a aprendizagem no trabalho, lançando bases para o seu reposicionamento em contexto de complexidade organizacional. 